DOSSIÊ FEDERALISMO

\title{
FEDERALISMO E DESCENTRALIZAÇÃO EM PERSPECTIVA COMPARADA: SOBRE SIGNIFICADOS E MEDIDAS ${ }^{1}$
}

\author{
Jonathan Rodden
}

\section{RESUMO}

Este artigo revê e redireciona a literatura empirica comparada sobre as causas e conseqüencias da descentralização e do federalismo. A "primeira geração" de estudos concebia a descentralização como um jogo de soma zero, de transferência de autoridade do centro para os governos subnacionais; partia das premissas da economia de bem-estar social e da teoria da escolha pública e empregava formas pouco precisas para medir a descentralização do gasto e o federalismo. Em contraste, ao definir diversas modalidades de federalismo e de descentralizações fiscal, política e de políticas; ao medi-las e ao explorar inte-rrelações entre países e ao longo do tempo, este trabalho apresenta um retrato mais preciso da descentralização e do federalismo, que fornece subsídios para explicar a crescente disjunção entre a teoria e as evidências encontradas em diferentes países. Assim, aponta na direção de uma "segunda geração" de trabalhos empíricos mais sofisticados, que levam a política e as instituições a sério.

PALAVRAS-CHAVE: federalismo; descentralização fiscal; descentralização política; descentralização de políticas; conceitos.

\section{INTRODUCC̃̃O}

A estrutura básica dos governos encontra-se em processo de transformação no mundo, à medida que a autoridade política e os recursos migram do controle dos governos centrais para os subnacionais. Embora cientistas políticos e economistas venham desenvolvendo uma variedade de teorias para explicar as causas e as conseqüências dessas mudanças, observa-se um atraso no que se refere a esforços sistemáticos para testar essas teorias empiricamente. Cada vez mais, os pesquisadores da área estão complementando os estudos de caso com análises de grandes conjuntos de dados que exploram variações diacrônicas e entre países. Embora as dificuldades para colher dados exijam que se trabalhe com proposições simples e de elevado nível de abstração, ainda assim é desejável testar hipóteses sobre federalismo e descentralização com base em informações acerca de um grande número de países e diversas décadas. Embora o escopo e a generalidade sejam as maiores vantagens oferecidas pelas

1 Este artigo foi publicado anteriormante na revista Comparative Politics, New York, v. 36, n. 4, November, 2004. Tradução de Míriam Adelman e Marta Arretche. regressões estatísticas nas análises comparadas, estas também podem criar problemas que ameaçam obscurecer ao invés de clarear os fatos.

Dados confiáveis de diversos países sobre descentralização e federalismo são escassos e os conceitos utilizados muitas vezes são tidos com complementares ou mesmo intercambiáveis. A visão dominante sobre descentralização retrata a transferência orgânica e organizada de autonomia política, fiscal e de gestão de políticas. Alguns estudos comparados procuram explicar a descentralização fiscal endogenamente (PANIZZA, 1999; GARRETT \& RODDEN, 2003); outros tratam a descentralização e o federalismo como exógenos e tentam medir seus efeitos sobre o crescimento econômico (DAVOODI \& ZOU, 1998) ou como proxies para accountability, corrupção ou qualidade da governança (TREISMAN, 2000a; FISMAN \& GATTI, 2002). Outros estudos examinaram suas implicações sobre o déficit fiscal, a inflação e a estabilidade macro-econômica (TREISMAN, 2000B; WIBBELS, 2000), enquanto uma literatura mais antiga examina o tamanho e o crescimento dos governos (CAMERON, 1978; OATES, 1985). Cada um desses estudos utiliza uma única e simples medida de descentralização 
fiscal, uma distinção binária entre estados federais e unitários ou ambos.

Crescente desilusão com a descentralização e o federalismo, especialmente entre os países em desenvolvimento, é o leitmotif mais evidente dessa literatura. Teorias otimistas, começando por Montesquieu e continuando ao longo da moderna economia do bem-estar social (OATES, 1972), enfatizaram as vantagens de revelação da informação e de accountability das estruturas governamentais mais descentralizadas. As teorias da escolha pública exploraram a possibilidade de que a mobilidade, em contextos descentralizados e de jurisdição múltipla, possa facilitar a adequação entre as preferências dos cidadãos e as políticas governamentais (TIEBOUT, 1956; BRETON \& SCOTT, 1978), produzir governos menores, mais eficientes e menos corruptos (HAYEK, 1939; BRENNNAN \& BUCHANAN, 1980), bem como, sob determinadas condições, mercados mais seguros e crescimento econômico mais rápido (WEINGAST, 1995). Porém, estudos empíricos recentes contestam essas teorias, apresentando evidências que associam a descentralização e o federalismo a níveis mais altos de percepção da corrupção (TREISMAN, 2000a), governos maiores (STEIN, 1999), instabilidade macro-econômica (WIBBELS, 2000) e, sob determinadas condições, menor crescimento (DAVOODI \& ZOU, 1998). Tais estudos freqüentemente apresentam conclusões que põem em dúvida os benefícios da descentralização e do federalismo.

Contudo, as distinções entre os variados tons de descentralização e federalismo ainda não foram encaradas com seriedade. Questões sobre desenho, conteúdo e forma da descentralização são tratadas superficialmente, não porque as teorias e as hipóteses relevantes sejam pouco diferenciadas, mas devido às dificuldades envolvidas na coleta de dados mais refinados. As deficiências dessas medidas freqüentemente são reconhecidas, mas defendidas como o custo necessário para construir uma amostra de tamanho suficiente para permitir fazer inferências confiáveis. Mas quão altos são esses custos? Será que os indicadores preferidos de descentralização realmente medem os conceitos utilizados nas teorias rele- vantes? Este artigo assume algumas licenças das regressões utilizadas em análises comparadas e apresenta algumas perguntas básicas sobre definições e medidas. Após distinguir e estabelecer relações entre tipos de descentralização e federalismo, argumento que as relações entre a teoria e a análise empírica da "primeira geração" de estudos são bastante tênues.

A primeira tarefa deste artigo é utilizar dados novos para apresentar uma descrição empírica e conceitualmente mais sólida das formas de descentralização e federalismo. Esse procedimento proporcionar-nos-á várias pistas importantes sobre as razões por que os estudos empíricos existentes destoam tanto das teorias normativas e às vezes entre si. Acima de tudo, em lugar de fortalecer a autoridade independente dos governos estaduais e municipais, a descentralização muitas vezes cria uma forma de governo mais complexa e entrelaçada que pouco se parece com as formas de descentralização previstas nos manuais sobre o federalismo fiscal ou nas teorias de escolha pública. Em segundo lugar, à luz destes fatos, o artigo reavalia o que se aprendeu com a primeira geração de estudos comparados e enfatiza formas de melhorar a coleta de dados, a teoria e os laços entre ambas.

\section{DESCENTRALIZAÇÃO}

A descentralização é freqüentemente concebida como a transferência de autoridade dos governos centrais para os governos locais, tomando-se como fixa a autoridade total dos governos sobre a sociedade e a economia. Os esforços para definir e medir a descentralização concentraram-se primordialmente na autoridade fiscal e, em grau menor, na autoridade política e da gestão de políticas.

\section{II.1. Descentralização fiscal}

A maior parte dos estudos empíricos sobre descentralização enfoca exclusivamente a distribuição das despesas e receitas entre níveis de governo. Esses estudos apóiam-se principalmente na publicação do FMI Government Finance Statistics Yearbook (daqui em diante, "GFS") para calcular a participação dos governos locais e regionais no total do gasto governamental. 
TABELA1 - VARIÁVEIS DE DESCENTRALIZAÇÃO FISCAL (MÉDIAS DOS ANOS 1990)

\begin{tabular}{|c|c|c|c|c|c|c|c|c|}
\hline & 1 & 2 & 3 & 4 & 5 & 6 & 7 & 8 \\
\hline & $\begin{array}{l}\text { Gastos } \\
\text { do gov. } \\
\text { local- } \\
\text { estados/ } \\
\text { Total de } \\
\text { gastos }\end{array}$ & $\begin{array}{l}\text { Transfe- } \\
\text { rências/ } \\
\text { Total } \\
\text { das } \\
\text { receitas } \\
\text { dos gov. } \\
\text { locais- } \\
\text { estados }\end{array}$ & $\begin{array}{l}\text { Receitas } \\
\text { próprias } \\
\text { dos } \\
\text { estados- } \\
\text { gov. } \\
\text { locais/ } \\
\text { Receita } \\
\text { total }\end{array}$ & $\begin{array}{l}\text { Transf.+ } \\
\text { receitas } \\
\text { compar- } \\
\text { tilhadas/ } \\
\text { Receita } \\
\text { dos } \\
\text { estados- } \\
\text { gov. } \\
\text { locais }\end{array}$ & $\begin{array}{l}\text { Receitas } \\
\text { próprias } \\
\text { dos } \\
\text { estados- } \\
\text { gov. } \\
\text { locais/ } \\
\text { Total da } \\
\text { receita }\end{array}$ & $\begin{array}{l}\text { Receitas } \\
\text { tributá- } \\
\text { rias dos } \\
\text { estados- } \\
\text { gov. } \\
\text { local/Re- } \\
\text { ceitas } \\
\text { totais } \\
\text { (autono- } \\
\text { mia } \\
\text { sobre } \\
\text { taxas) }\end{array}$ & $\begin{array}{l}\text { Receitas } \\
\text { tributá- } \\
\text { rias dos } \\
\text { estados- } \\
\text { gov. } \\
\text { locais } \\
\text { (autono- } \\
\text { mia } \\
\text { sobre } \\
\text { taxas e } \\
\text { bases) }\end{array}$ & $\begin{array}{l}\text { Autono- } \\
\text { mia para } \\
\text { contrair } \\
\text { emprés- } \\
\text { timos }\end{array}$ \\
\hline Argentina & 0,44 & - & - & 0,56 & 0,18 & - & - & 4,0 \\
\hline Austrália & 0,50 & 0,40 & 0,32 & 0,37 & 0,33 & - & - & 2,5 \\
\hline Áustria & 0,34 & 0,27 & 0,27 & 0,58 & 0,16 & 0,008 & 0,004 & 1,6 \\
\hline Bélgica & 0,12 & 0,56 & 0,06 & - & - & 0,048 & 0,004 & - \\
\hline Bolívia & 0,21 & 0,09 & 0,18 & 0,43 & 0,11 & - & - & 1,5 \\
\hline Botsuana & 0,03 & 0,83 & 0,01 & 0,84 & 0,01 & - & - & 1,0 \\
\hline Brasil & 0,41 & 0,34 & 0,28 & 0,36 & 0,27 & - & - & 4,5 \\
\hline Bulgária & 0,19 & 0,35 & 0,15 & 0,92 & 0,02 & - & - & 1,0 \\
\hline Canadá & 0,65 & 0,26 & 0,51 & 0,32 & 0,47 & 0,321 & 0,299 & 2,7 \\
\hline Colômbia & - & - & - & 0,38 & - & - & - & 3,0 \\
\hline Dinamarca & 0,54 & 0,09 & 0,31 & 0,43 & 0,32 & 0,174 & 0 & 1,5 \\
\hline Finlândia & 0,41 & 0,43 & 0,33 & 0,36 & 0,31 & 0,196 & 0 & 3,0 \\
\hline França & 0,19 & 0,73 & 0,13 & 0,39 & 0,12 & - & - & 3,0 \\
\hline Alemanha & 0,45 & 0,72 & 0,34 & 0,70 & 0,13 & 0,0090 & 0,0002 & 2,5 \\
\hline Guatemala & 0,10 & 0,40 & 0,04 & 0,67 & 0,03 & - & - & 2,0 \\
\hline Hungria & 0,10 & 0,66 & - & - & - & 0,018 & 0 & - \\
\hline Islândia & 0,23 & 0,19 & 0,23 & - & - & 0,184 & 0 & - \\
\hline Índia & 0,49 & 0,43 & 0,33 & 0,42 & 0,34 & - & - & 2,5 \\
\hline Indonésia & 0,13 & 0,73 & 0,03 & - & - & - & - & - \\
\hline Irlanda & 0,29 & 0,72 & 0,09 & 0,74 & 0,08 & - & - & 1,8 \\
\hline Israel & 0,14 & 0,40 & 0,08 & 0,38 & 0,09 & - & - & 2,4 \\
\hline Itália & 0,23 & 0,66 & 0,09 & 0,80 & 0,05 & - & - & 2,5 \\
\hline Malásia & 0,14 & 0,19 & 0,16 & - & - & - & - & - \\
\hline México & 0,23 & 0,11 & 0,20 & 0,59 & 0,09 & 0,018 & 0,018 & 2,6 \\
\hline Holanda & 0,30 & 0,70 & 0,09 & 0,70 & 0,09 & 0,010 & 0 & 2,3 \\
\hline Nigéria & 0,48 & 0,86 & 0,09 & 0,86 & 0,09 & - & - & 1,0 \\
\hline Noruega & 0,35 & 0,40 & 0,22 & 0,39 & 0,22 & 0,004 & 0 & 1,6 \\
\hline Peru & 0,23 & 0,73 & 0,07 & 0,05 & 0,23 & - & - & 2,5 \\
\hline Filipinas & 0,08 & 0,46 & 0,05 & 0,41 & 0,06 & - & - & 1,0 \\
\hline Polônia & 0,17 & 0,31 & 0,13 & 0,54 & 0,09 & 0,032 & 0 & 2,0 \\
\hline Portugal & 0,09 & 0,48 & 0,05 & 0,40 & 0,06 & 0,011 & 0,009 & 2,5 \\
\hline Paraguai & 0,02 & - & 0,01 & 0,23 & 0,01 & - & - & 2,0 \\
\hline Romênia & 0,11 & 0,44 & 0,07 & 0,44 & 00,7 & - & - & 1,0 \\
\hline Espanha & 0,36 & 0,60 & 0,16 & 0,56 & 0,17 & 0,053 & 0,022 & 2,5 \\
\hline Suécia & 0,37 & 0,18 & 0,33 & 0,20 & 0,32 & 0,183 & 0,006 & 3,0 \\
\hline Suíça & 0,55 & 0,25 & 0,41 & 0,19 & 0,45 & 0,179 & 0,113 & 3,0 \\
\hline Tailândia & 0,06 & 0,28 & 0,05 & - & - & - & - & - \\
\hline Inglaterra & 0,29 & 0,71 & 0,09 & 0,74 & 0,08 & 0,040 & 0 & 1,5 \\
\hline EUA & 0,53 & 0,30 & 0,42 & 0,34 & 0,39 & 0,177 & 0,177 & 3,0 \\
\hline
\end{tabular}

FONTE: o autor, a partir de: colunas 1 a 3: GFS; colunas 4, 5 e 8: Rodden (2002); colunas 6 e 7: OECD (1999). 
A primeira coluna da Tabela 1 apresenta dados sobre a descentralização de gastos para todos os países para os quais o GFS fornece uma boa cobertura ao longo dos anos 1990. Bem mais do que a metade do gasto público é realizada pelos níveis regionais e local, em federações descentralizadas como Canadá e Suíça, enquanto essa proporção é inferior a $4 \%$ em alguns países altamente centralizados da África. Esses dados permitem-nos traçar ainda - o que é mais importante - a evolução da descentralização fiscal ao longo do tempo.

FIGURA 1 - INDICADORES DE DESCENTRALIZAÇÃO SELECIONADOS (SÉRIES TEMPORAIS)

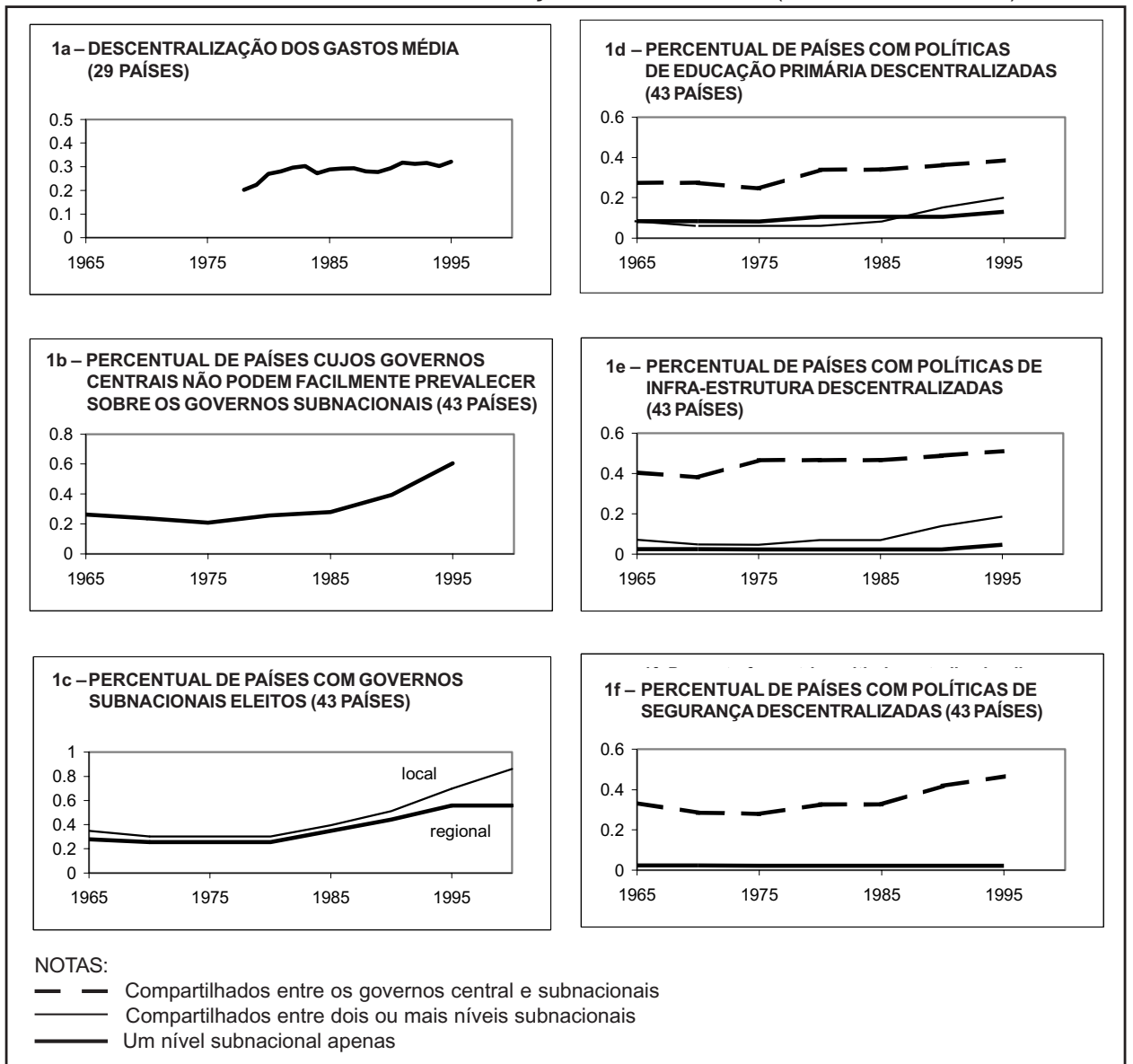

FONTES: 1a: GFS; 1b: Henderson (s/d); 1c: Henderson (s/d) e World Bank (2000); 1d a 1f: Henderson (s/d).

A Figura 1a apresenta as médias da participação dos governos locais e regionais no total do gasto, para um conjunto de 29 países para os quais existem séries temporais a partir de 1978. Observa-se uma tendência ascendente notável: em 1978, em torno de $20 \%$ dos gastos eram feitos nos níveis subnacionais; em 1995, essa média havia saltado para mais de $32 \%$. Contudo, isso de maneira alguma representa uma tendência universal. Em alguns países, a distribuição da autoridade de gas- to retornou para os governos centrais nos anos 1990, enquanto a descentralização fiscal prevaleceu mais na Espanha e em boa parte da América Latina.

Entretanto, um olhar rápido sobre esses dados não inspira grande confiança com relação à sua utilidade como uma medida composta de descentralização da autoridade. Por exemplo, a Dinamarca é o terceiro país mais descentralizado do mundo, segundo a Tabela 1 - ainda mais des- 
centralizado do que os EUA - embora o governo central regule quase todos os aspectos das finanças dos governos locais. A Nigéria aparece em sétimo lugar, mesmo que os estados, durante o período de regime militar, fossem pouco mais do que postos administrativos do governo central.

Em resumo, é difícil interpretar os dados sobre a descentralização do gasto sem informações adicionais sobre a estrutura regulatória das finanças subnacionais. A maior parte dos argumentos teóricos que enfatizam os ganhos de eficiência obtidos pela descentralização (assim como os argumentos mais recentes que apontam para os perigos desta última) implicitamente assumem que os avanços - deterioração - em "responsividade" [responsiveness] ou os incentivos para os esforços dos governos locais derivam da maior autonomia em relação em relação ao governo central central, assim como na teoria da organização industrial, para a maior parte da literatura, a essência da descentralização reside no fato de que ela permite maior discrição para os governos locais combinada à limitação de acesso do centro à informação, restringindo assim a capacidade do último de anular decisões locais ex post (QIAN \& WEINGAST, 1997). Ao comparar firmas, se as divisões regionais da firma $\mathrm{A}$ gastam mais do que as divisões regionais da firma $\mathrm{B}$, isso não necessariamente é reflexo de uma descentralização maior da primeira se os gerentes regionais da firma $\mathrm{A}$ estão mais sujeitos a um controle rígido por parte da sede central e suas decisões sofrem intervenção freqüente, enquanto a firma B é essencialmente um conglomerado. No mesmo sentido, a descentralização do gasto governamental pode dizer muito pouco sobre o locus da autoridade.

Uma consideração importante diz respeito às fontes de financiamento da descentralização do gasto: se ela provém de transferências intergovernamentais, receita compartilhada com o centro de acordo com uma fórmula fixa ou da arrecadação de receitas próprias, tais como impostos ou tarifas pagas por usuários, ou ainda empréstimos. Até recentemente, quase todos os estudos comparados ignoraram essas diferenças. O GFS de fato inclui uma linha nas suas contas das receitas subnacionais chamada "transferências" [grants], mas para muitos países elas não incluem as transferências constitucionalmente compartilhadas. Pode-se utilizar essa informação para calcular a dependência dos governos locais e regionais em relação às transferências. Essas médi- as estão apresentadas na segunda coluna da Tabela 1. Além disso, pode-se obter uma medida alternativa de descentralização fiscal, calculandose a participação das receitas próprias dos governos locais na receita governmental total (terceira coluna da Tabela 1). Embora seja uma fonte úutil para observar a variação ao longo do tempo, devese tomar cuidado ao fazer inferências baseadas na variação entre países, porque os registros sobre as receitas de transferências e as receitas próprias não parecem ser consistentes entre os países.

Uma forma de obter medidas mais seguras do que as do GFS seria utilizar informações dos próprios países, para construir uma medida de autonomia de receitas dos governos subnacionais que não codifique automaticamente receitas derivadas de mecanismos de partilha tributária como receita própria. A quarta coluna da Tabela 1 apresenta uma medida da participação das transferências mais receitas partilhadas no total das receitas dos governos subnacionais e a coluna seguinte apresenta uma medida das receitas próprias como parcela da receita total (RODDEN, 2002). Esta última é uma alternativa à variável simples "descentralização do gasto" - representa uma tentativa de medir a parcela da receita governamental total que é efetivamente arrecadada por meio dos esforços dos governos subnacionais.

Contudo, mesmo essa variável ainda exagera o grau de autonomia dos governos subnacionais com relação às suas receitas. Embora os governos subnacionais possam arrecadar receitas chamadas de "fonte própria", o governo central pode ainda manter o poder de decisão acerca das alíquotas e das bases tributárias, deixando aos governos subnacionais o simples papel de coletar impostos de acordo com a determinação central. Um estudo recente da Organização para a Cooperação e o Desenvolvimento Econômicos (OCDE) examina esse problema complexo, mas infelizmente aborda apenas um pequeno número de países (OECD, 1999). Tal estudo permite-nos calcular duas variáveis adicionais: a parcela do total das receitas de impostos sobre a qual os governos subnacionais possuem autonomia plena para fixar (1) as alíquotas de seus próprios impostos e (2) as taxas e as fontes de seus impostos. Essas variáveis, também apresentadas na Tabela 1, apresentam um retrato muito diferente da autonomia fiscal dos governos subnacionais. Vários países em que os governos subnacionais são responsáveis 
por uma grande parcela do total do gasto (coluna 1) e da taxação (coluna 5), esses governos subnacionais têm muito pouca autonomia sobre as alíquotas e as fontes de tributação (coluna 7). De fato, este estudo deixa claro que os EUA, o Canadá e a Suíça são um caso à parte quando se trata da autoridade autônoma sobre as receitas subnacionais. Um objetivo importante para a coleta de novos dados seria a expansão e aperfeiçoamento do estudo da OCDE, especialmente para os países em desenvolvimento.

TABELA 2 - CORRELAÇÃO DE COEFICIENTES DE VARIÁVEIS DE DESCENTRALIZAÇÃO (ANOS 1990)

\begin{tabular}{|c|c|c|c|c|c|c|c|c|c|c|}
\hline & $\begin{array}{l}\text { Gastos do } \\
\text { gov. local- } \\
\text { estados/ } \\
\text { Total de } \\
\text { gastos }\end{array}$ & $\begin{array}{l}\text { Transfe- } \\
\text { rências/ } \\
\text { Total das } \\
\text { receitas } \\
\text { dos gov. } \\
\text { locais- } \\
\text { estados }\end{array}$ & $\begin{array}{l}\text { Receitas } \\
\text { próprias } \\
\text { dos } \\
\text { estados- } \\
\text { gov. } \\
\text { locais/Re- } \\
\text { ceita total }\end{array}$ & $\begin{array}{l}\text { Transf.+ } \\
\text { receitas } \\
\text { comparti- } \\
\text { lhadas/ } \\
\text { Receita } \\
\text { dos es- } \\
\text { tados-gov. } \\
\text { locais }\end{array}$ & $\begin{array}{l}\text { Receitas } \\
\text { próprias } \\
\text { dos esta- } \\
\text { dos-gov. } \\
\text { locais/To- } \\
\text { tal da } \\
\text { receita }\end{array}$ & $\begin{array}{l}\text { Receitas } \\
\text { tributárias } \\
\text { dos esta- } \\
\text { dos-gov. } \\
\text { local/ Re- } \\
\text { ceitas to- } \\
\text { tais (auto- } \\
\text { nomia so- } \\
\text { bre taxas) }\end{array}$ & $\begin{array}{l}\text { Receitas } \\
\text { tributárias } \\
\text { dos esta- } \\
\text { dos-gov. } \\
\text { locais (au- } \\
\text { tonomia } \\
\text { sobre ta- } \\
\text { xas e ba- } \\
\text { ses) }\end{array}$ & $\begin{array}{l}\text { Autono- } \\
\text { mia para } \\
\text { contrair } \\
\text { emprés- } \\
\text { timos }\end{array}$ & $\begin{array}{l}\text { Autono- } \\
\text { mia } \\
\text { política }\end{array}$ & $\begin{array}{l}\text { Eleições } \\
\text { subna- } \\
\text { cionais }\end{array}$ \\
\hline $\begin{array}{l}\text { Transfe- } \\
\text { rências/ } \\
\text { Receitas } \\
\text { estaduais }\end{array}$ & $\begin{array}{l}-0,1958 \\
35\end{array}$ & & & & & & & & & \\
\hline $\begin{array}{l}\text { Receitas } \\
\text { estaduais } \\
\text { próprias/ } \\
\text { Receitas } \\
\text { totais }{ }^{* *}\end{array}$ & $\begin{array}{l}0,8729^{*} \\
36\end{array}$ & $\begin{array}{l}-0,5908^{*} \\
35\end{array}$ & & & & & & & & \\
\hline $\begin{array}{l}\text { Transfe- } \\
\text { rências+ } \\
\text { receitas } \\
\text { comparti- } \\
\text { Ihadas/ } \\
\text { Receitas } \\
\text { estaduais }\end{array}$ & $\begin{array}{l}-0,1668 \\
32\end{array}$ & $\begin{array}{l}0,4600^{*} \\
30\end{array}$ & $\begin{array}{l}-0,3724^{*} \\
31\end{array}$ & & & & & & & \\
\hline $\begin{array}{l}\text { Receitas } \\
\text { estaduais } \\
\text { próprias/ } \\
\text { Receitas } \\
\text { totais }{ }^{* * *}\end{array}$ & $\begin{array}{l}0,8419^{*} \\
32\end{array}$ & $\begin{array}{l}-0,4182^{*} \\
30\end{array}$ & $\begin{array}{l}0,8995^{*} \\
31\end{array}$ & $\begin{array}{l}-0,5979^{*} \\
32\end{array}$ & & & & & & \\
\hline $\begin{array}{l}\text { Receitas } \\
\text { fiscais } \\
\text { estadu- } \\
\text { ais/Re- } \\
\text { ceitas } \\
\text { totais } \\
\text { (autono- } \\
\text { mia de } \\
\text { taxas) }\end{array}$ & $\begin{array}{l}0,6407^{*} \\
19\end{array}$ & $\begin{array}{l}-0,3817 \\
18\end{array}$ & $\begin{array}{l}0,7257^{*} \\
18\end{array}$ & $\begin{array}{l}-0,6557^{*} \\
16\end{array}$ & $\begin{array}{l}0,8698^{*} \\
16\end{array}$ & & & & & \\
\hline $\begin{array}{l}\text { Receitas } \\
\text { fiscais } \\
\text { estaduais } \\
\text { /Receitas } \\
\text { totais } \\
\text { (autono- } \\
\text { mias de } \\
\text { taxa e de } \\
\text { base) }\end{array}$ & $\begin{array}{l}0,6399^{*} \\
19\end{array}$ & $\begin{array}{l}0,2278 \\
18\end{array}$ & $\begin{array}{l}0,6806^{*} \\
18\end{array}$ & $\begin{array}{l}-0,434 \\
16\end{array}$ & $\begin{array}{l}0,7027^{*} \\
16\end{array}$ & $\begin{array}{l}0,6797^{*} \\
19\end{array}$ & & & & \\
\hline $\begin{array}{l}\text { Autono- } \\
\text { mia para } \\
\text { contrair } \\
\text { emprés- } \\
\text { timos }\end{array}$ & $\begin{array}{l}0,4126^{*} \\
32\end{array}$ & $\begin{array}{l}-0,3545 \\
30\end{array}$ & $\begin{array}{l}0,4953^{*} \\
31\end{array}$ & $\begin{array}{l}-0,4510^{*} \\
34\end{array}$ & $\begin{array}{l}0,5126^{*} \\
32\end{array}$ & $\begin{array}{l}0,2246 \\
16\end{array}$ & $\begin{array}{l}0,2741 \\
16\end{array}$ & & & \\
\hline $\begin{array}{l}\text { Autono- } \\
\text { mia } \\
\text { política }\end{array}$ & $\begin{array}{l}0,5130^{*} \\
23\end{array}$ & $\begin{array}{l}0,1499 \\
19\end{array}$ & $\begin{array}{l}0,3402 \\
19\end{array}$ & $\begin{array}{l}0,0833 \\
19\end{array}$ & $\begin{array}{l}0,1067 \\
17\end{array}$ & $\begin{array}{l}0,3417 \\
10\end{array}$ & $\begin{array}{l}0,3117 \\
10\end{array}$ & $\begin{array}{l}0,1038 \\
19\end{array}$ & & \\
\hline
\end{tabular}

FONTES: o autor, exceto: ** GFS; *** Rodden (2002).

NOTAS:

1. Coeficientes de simples correlação pairwise.

2. Número de casos sobrepostos em itálico.

3. * Significância de 0,05. 
A Tabela 2 apresenta uma matriz de dupla entrada de coeficientes de correlação para todas as variáveis contempladas neste artigo. O número de casos que servem de base para as correlações aparece em itálico. As variáveis referentes à modalidade de descentralização, baseada na "receita de fonte própria", calculadas a partir do GFS e das informações dos próprios países, apresentam correlações elevadas, de 0,9 . Seguindo a primeira coluna para baixo, encontram-se correlações relativamente elevadas $(0,87$ e 0,84$)$ entre as variáveis "descentralização do gasto" e "arrecadação de recursos de fonte própria", calculadas com base nas informações do GFS e nas informações dos próprios países. Contudo, para a amostra menor da OCDE, a correlação entre a descentralização do gasto e qualquer uma das variáveis referentes à arrecadação local autônoma de impostos cai para aproximadamente 0,64 .

Adicionalmente, os governos centrais podem tentar restringir a autonomia fiscal dos governos subnacionais, não somente por meio de transferências condicionadas e da regulação da arrecadação local de impostos, como também impondo limitações formais à obtenção de empréstimos pelos governos subnacionais. A capacidade de aceder os mercados de crédito ou outras fontes de financiamento do déficit é um componente importante da autonomia fiscal dos governos subnacionais. Um índice criado pelo Banco Interamericano de Desenvolvimento considera as exigências para autorização de endividamento, os limites quantitativos e as restrições ao uso de dívidas impostas pelo governo central, assim como a possibilidade de obter empréstimos dos bancos e empresas públicas de propriedade dos governos subnacionais (em 1995). Essa variável, com escala de 1 a 5 , é apresentada na última coluna da Tabela 1. A Tabela 2 mostra que a autonomia para obter empréstimos está positivamente correlacionada às medidas de gastos e de descentralização das receitas e negativamente correlacionada às dependência de transferências (cf. HAGEN \& EICHENGREEN, 1996; RODDEN, 2002).

\section{II.2. A descentralização de políticas}

A descentralização de políticas raramente é examinada pelos estudos empíricos, porque é muito difícil medí-la. Afortunadamente, Vernon Henderson recentemente tomou para si essa tarefa (HENDERSON, 2000). Em primeiro lugar,
Henderson perguntou se o governo central tem o direito legal de sobrepor-se às decisões tomadas pelos níveis subnacionais com relação às políticas sob sua competência "com uma facilidade que coloque em questão sua autoridade" (HENDERSON, s/d). Embora essa codificação envolva uma certa liberdade de critérios, a figura $1 \mathrm{~b}$ mostra que, em 1975, 21\% dos governos centrais da amostra de Henderson não possuíam o direito legal de anular as decisões e políticas tomadas localmente, mas em 1995 essa porcentagem havia pulado para $60 \%$. Em segundo lugar, Henderson perguntou que nível do governo é responsável pela tomada de decisões em cada uma de três áreas de política: educação básica (autoridade sobre currículo e contratação ou demissão de professores), infra-estrutura (construção local de estradas) e a força policial local. Os gráficos das figuras $1 \mathrm{~d}$ a $1 \mathrm{f}$ mostram uma tendência inequívoca na direção de uma influência maior dos governos locais e regionais em cada uma dessas áreas.

Talvez o aspecto mais impressionante desses gráficos seja a prevalência de autoridade compartilhada. A porção da amostra em que existe autoridade compartilhada entre o governo central e um ou mais dos governos locais está indicada por meio de uma linha pontilhada. Muito raramente os governos centrais cedem autonomia plena aos governos subnacionais. Na vasta maioria dos casos, a descentralização envolve um movimento de uma situação de completo controle do governo central para a de um envolvimento conjunto entre o centro e uma ou mais unidades subnacionais. Mesmo nos casos em que o governo central não está envolvido, a autoridade é freqüentemente compartilhada por dois ou mais níveis de governo (apresentados na tabela com tipo normal). Finalmente, as situações em que apenas um nível de governo está envolvido na elaboração das políticas (apresentado em negrito) são extremadamente raras. A literatura sobre o federalismo fiscal assume o "pressuposto de que a provisão de serviços públicos deve estar localizada nos níveis menores do governo, abrangendo, espacialmente, os custos e benefícios relevantes" (OATES, 1999, p. 1 124). A prescrição normativa e, em última instância, as teorias positivas que dela são derivadas supõem uma nítida compartimentalização da autoridade, de acordo com algo que se assemelha ao princípio do subsidiariedade, combinada à autoridade compartilhada ocasionalmente, para as tarefas em 
que os custos e os benefícios relevantes recaem entre os níveis de governo. Contudo, os dados do Gráfico 1 mostram que os governos centrais e regionais estão freqüentemente envolvidos até mesmo em assuntos relacionados ao currículo, contratação e demissão de professores do ensino fundamental, assim como decisões sobre a construção de estradas municipais.

É possível transformar os dados sobre políticas do Gráfico 1 em uma medida simples da autonomia dos governos subnacionais sobre as políticas. Uma estratégia razoável consiste em atribuir dois pontos para os países que não têm controle central sobre as políticas dos governos subnacionais, dois pontos para cada área de política em que o controle é exercido exclusivamente pelos governos regionais ou locais e um ponto para as áreas de política em que os governos subnacionais compartilham suas decisões com o centro. Para 1995, o índice vai de zero a sete. A Tabela 2 mostra que essa variável apresenta uma correlação de 0,51 com a descentralização do gasto, mas é interessante notar que ela não é significativamente correlacionada com nenhuma das outras medidas de decentralização.

\section{II.3. A descentralização política}

A seguir, é possível obter algum conhecimento sobre a descentralização política acompanhando eleições regionais e locais ao longo do tempo. O Gráfico 1c apresenta a parte da amostra em que os governos regionais e locais são eleitos por voto popular, mostrando mais uma vez uma tendência evidente em direção à descentralização. Enquanto somente $30 \%$ dos governos locais da amostra eram eleitos em 1970, em 1999 essa parcela havia aumentado para $86 \%$. Para muitos desses países, essa mudança representa parte de uma mudança maior, do autoritarismo para a democracia, no final dos anos 1980 e início dos anos 1990.

Um índice simples de descentralização política, variando de zero a dois, atribui um ponto para cada nível subnacional em que os membros do poder Executivo foram eleitos por voto popular em 1995. Não surpreende que a Tabela 2 mostre que as autoridades locais eleitas por voto popular gozem de maior grau de autonomia na gestão das políticas do que as autoridades nomeadas e que tenham poder de decisão sobre uma proporção maior das despesas públicas.
Embora seja útil a distinção binária entre autoridades eleitas e nomeadas, variações mais sutis na descentralização política entre sistemas que elegem diretamente seus governos subnacionais são mais difíceis de quantificar, embora sejam de grande importância. Acima de tudo, é importante avaliar a relação entre as arenas eleitorais de níveis local e central. Por exemplo, a lista de candidatos que competem nas eleições locais pode ser escolhida pelos dirigentes do partido no governo central. Do outro lado do espectro, as autoridades locais ou estaduais podem desempenhar um papel-chave na seleção de candidatos para as eleições governamentais do governo central. Por exemplo, na Austrália e na Alemanha, as listas dos partidos para as eleições federais são elaboradas pelos líderes partidários estaduais, assim como, nos EUA, os estados desempenham um papel fundamental na seleção dos candidatos à presidência. Embora essas questões sejam examinadas em alguns poucos estudos de caso (GARMAN, HAGGARD \& WILLIS, 2001), uma meta valiosa para as pesquisas futuras seria a compilação de um conjunto de dados comparativos de diversos países.

De maneira mais abstrata, essas variáveis são interessantes em caso de querermos avaliar a independência relativa (ou interdependência) das arenas eleitorais dos níveis central e subnacionais. Por exemplo, as eleições dos governos estaduais nos EUA são conhecidamente influenciadas pela avaliação que os eleitores fazem do presidente e seus colegas de partido. Governadores - sem sorte - podem ser apenados pelos efeitos de punição das eleições realizadas na metade do mandato, enquanto outros - mais felizardos - podem pegar carona na popularidade do presidente em períodos de prosperidade econômica. Em um exemplo mais extremo das externalidades entre eleições centrais e subnacionais, os eleitores alemães encaram as eleições estaduais como competições federais de metade do mandato, pois determinam diretamente a composição partidária da poderosa câmara alta. Por outro lado, David Samuels sugere que no Brasil, onde os estados são os distritos eleitorais, as eleições federais sofrem forte influência da política do nível estadual em que os governadores jogam um papel crítico (SAMUELS, 2000).

O sucesso de uma autoridade subnacional tem um componente que se baseia nas avaliações acerca de seu desempenho no nível local e um com- 
ponente que provém da avaliação de seu partido no nível nacional. Não obstante essa "carona", vários estudos demonstram vínculos claros entre o desempenho fiscal no plano estadual e o desempenho macro-econômico e os resultados das eleições para Governador, nos EUA. Assim, as chances de reeleição dos governadores nos EUA têm claros componentes nacionais e estaduais. Uma estimativa da dimensão desses componentes para as autoridades subnacionais em diversos países dir-nos-ia muito sobre sua motivação, por exemplo, para a cooperação intergovernamental, o esforço local ou a disciplina fiscal.

Uma avaliação menos precisa, porém mais operacional, da relação entre as arenas eleitorais centrais e subnacionais foi sugerido primeiramente por William Riker e Ronald Shaps (1957) e foi empregada em uma amostra de 14 federações desde os anos 1970 (RODDEN \& WIBBELS, 2002): o número de governadores de nível estadual ou provincial com a mesma filiação partidária do poder Executivo federal. Esse dado permite observar as variações na (des)centralização política ao longo do tempo e facilita comparações úteis entre países. Permite acompanhar, por exemplo, o dramático declínio da dominação do Partido do Congresso na Índia, a erosão gradual do domínio do PRI (Partido Revolucionário Institucional) no México, a fragmentação do sistema federal brasileiro e os episódios de autoritarismo e federalismo democrático na Nigéria. Embora seja baixo o número de casos que coincidem, a Tabela 2 mostra que, na média, nos anos 1990, essa "harmonia partidária" está negativamente correlacionada com medidas de descentralização fiscal e política.

\section{FEDERALISMO}

O federalismo não é uma distribuição particular de autoridade entre governos, mas sim um processo - estruturado por um conjunto de instituições - por meio do qual a autoridade é distribuída e redestribuída. $\mathrm{O}$ federalismo remete-se à palavra fredus, no latim, que significa "contrato". A palavra veio a ser usada para descrever acordos cooperativos entre estados, geralmente para finalidades de defesa. Acordos formais e contratos implicam reciprocidade: qualquer que seja o propósito, os envolvidos devem cumprir alguma obrigação mútua. Se o governo central pode obter tudo o que deseja dos governos locais por meio de simples atos administrativos, faz pouco sentido encarar ambos como engajados em uma relação contratual ou federal. O federalismo significa que para algum subconjunto das decisões ou atividades do govero central, torna-se necessário obter o consentimento ou a cooperação ativa das unidades subnacionais.

Antes de examinar os detalhes das instituições que balizam os contratos federais, é importante compreender como e porque os contratos federais fazem-se pela primeira vez. Tanto a definição quanto a operação do federalismo estão imersas nas condições históricas que fizeram emergir o contrato original. William Riker (1964) argumenta que as federações modernas surgiram de negociações que visavam a garantir defesa militar contra um inimigo comum, embora seja possível acrescentar-se outros bens coletivos como o livre comércio e uma moeda comum. As alianças e as confederações costumam sofrer de instabilidade, comportamento oportunista e problemas de ação coletiva; contudo, se os incentivos para a cooperação são suficientemente fortes e os incentivos políticos são adequadamente alinhados, os representantes das entidades envolvidas podem negociar uma nova estrutura de governo baseada em um governo central com forte autoridade e regras decisórias que exigem algo menos que a unanimidade. Uma vez feito esse contrato, ele toma vida própria e continua vigendo mesmo após a derrota do inimigo ou a conquista de um mercado ou moeda comum. Alfred Stepan (1999) identifica um segundo caminho em direção ao federalismo. Muitos estados multinacionais formaram-se não por meio de acordos voluntárias, mas por meio da conquista e do colonialismo. Diante do desafio de manter unido um estado multinacional, um pacto federal torna-se necessário, para conservar a unidade nacional e evitar os temores de exploração interétnica.

Em ambos os cenários, o contrato federal original é um acordo sobre a composição e os poderes do governo central, bem como sobre as "regras do jogo" que estruturarão as futuras interações entre esse governo e as unidades que o compõem. Os efeitos da barganha original tornam as federações diferentes dos sistemas unitários. As unidades não cederão autoridade ao centro sem salvaguardas contra a exploração futura, seja por parte do centro mesmo, seja por parte dos outros estados. Desse modo, os acordos federais geralmente incluem: a) uma constituição que proteja a soberania e a autonomia das unidades, incluindo em alguns casos b) cláusulas que lhes 
atribuem todos os "poderes residuais" que foram explicitamente atribuídos ao centro; a credibilidade dessa legislação muitas vezes está vinculada à presença de c) um tribunal constitucional forte e independente; mais importante, acordos federais exigem d) maiorias ou supermaiorias das unidades territoriais para efetuar uma ampla gama de mudanças nas políticas - especialmente mudanças na distribuição vertical básica de autoridade política e fiscal ou na Constituição.

Desde a Filadélfia de 1776 até a Reunião de Cúpula da Comunidade Européia em Nice no ano 2000 , está claro que, na adoção de um acordo federal, as maiores preocupações relativas à possibilidade de exploração provêm dos pequenos territórios que seriam sistematicamente derrotados se os votos fossem distribuídos de acordo com a população. Assim, estados pequenos tendem a insistir em esquemas de representação baseados no território, enquanto estados grandes defendem a representação proporcional à população. $\mathrm{O}$ compromisso geralmente envolve uma câmara baixa de base demográfica e uma câmara alta que sobre-representa os estados pequenos ${ }^{2}$. Dados comparativos coletados por David Samuels e Richard Snyder mostram que as federações apresentam níveis muito mais elevados de sobrerepresentação da câmara alta do que os sistemas unitários (SAMUELS \& SNYDER, 2001).

Portanto, o federalismo é uma forma de agregação de preferências que freqüentemente depende de acordos entre os governos territoriais ou seus representantes, em contraste com o princípio majoritário (CREMER \& PALFREY, 1999). Mas isso de modo algum implica um conceito binário. A Tabela 3 retrata um continuum que reflete o papel dos governos territoriais nos processos de elaboração de políticas do governo central.

TABELA 3 - PAPEL DOS GOVERNOS TERRITORIAIS NO PODER LEGISLATIVO

\begin{tabular}{|l|l|l|l|l|l|l|}
\multicolumn{9}{|c}{ Unitário } \\
\hline $\begin{array}{l}\text { Unidades } \\
\text { de decisão }\end{array}$ & Indivíduos & $\begin{array}{l}\text { Represen- } \\
\text { tantes } \\
\text { distritais } \\
\text { eleitos que } \\
\text { não } \\
\text { correspon- } \\
\text { dem aos } \\
\text { governos } \\
\text { territoriais }\end{array}$ & $\begin{array}{l}\text { Represen- } \\
\text { tantes } \\
\text { distritais } \\
\text { eleitos que } \\
\text { correspon- } \\
\text { dem aos } \\
\text { governos } \\
\text { territoriais }\end{array}$ & $\begin{array}{l}\text { Represen- } \\
\text { tantes } \\
\text { distritais } \\
\text { eleitos que } \\
\text { correspon- } \\
\text { dem aos } \\
\text { governos } \\
\text { territoriais }\end{array}$ & $\begin{array}{l}\text { Represen- } \\
\text { tantes } \\
\text { distritais } \\
\text { indicados } \\
\text { pelos } \\
\text { governos } \\
\text { territoriais }\end{array}$ & $\begin{array}{l}\text { Represen- } \\
\text { tantes } \\
\text { distritais } \\
\text { indicados } \\
\text { pelos } \\
\text { governos } \\
\text { territoriais }\end{array}$ \\
\hline $\begin{array}{l}\text { Regra da } \\
\text { representa- } \\
\text { ção distrital }\end{array}$ & N/d & $\begin{array}{l}\text { Uma } \\
\text { pessoa, um } \\
\text { voto }\end{array}$ & $\begin{array}{l}\text { Uma } \\
\text { pessoa, um } \\
\text { voto }\end{array}$ & $\begin{array}{l}\text { Sobre-re- } \\
\text { presentação }\end{array}$ & $\begin{array}{l}\text { Sobre-re- } \\
\text { presenta- } \\
\text { ção }\end{array}$ & $\begin{array}{l}\text { Sobre-re- } \\
\text { presentação }\end{array}$ \\
\hline $\begin{array}{l}\text { Requisitos } \\
\text { para } \\
\text { mudanças } \\
\text { nas políticas }\end{array}$ & Maioria & $\begin{array}{l}\text { Maioria } \\
\text { simples }\end{array}$ & $\begin{array}{l}\text { Maioria } \\
\text { simples }\end{array}$ & $\begin{array}{l}\text { Maioria } \\
\text { simples }\end{array}$ & $\begin{array}{l}\text { Maioria } \\
\text { simples }\end{array}$ & $\begin{array}{l}\text { Maioria } \\
\text { qualificada } \\
\text { ou super- } \\
\text { maioria }\end{array}$ \\
\hline Exemplo & $\begin{array}{l}\text { Assembléia } \\
\text { da cidade } \\
\text { (town } \\
\text { meeting) }\end{array}$ & $\begin{array}{l}\text { Parlamento } \\
\text { britâncio }\end{array}$ & $\begin{array}{l}\text { Câmara alta } \\
\text { italiana }\end{array}$ & $\begin{array}{l}\text { Senado } \\
\text { estaduni- } \\
\text { dense }\end{array}$ & $\begin{array}{l}\text { Bundesrat } \\
\text { alemão }\end{array}$ & $\begin{array}{l}\text { Conselho de } \\
\text { Ministros da } \\
\text { União } \\
\text { Européia }\end{array}$ \\
\hline
\end{tabular}

FONTE: o autor

NOTA: n/d: não disponível.

No extremo esquerdo, as decisões são tomadas por maiorias de indivíduos - os distritos territoriais não desempenham nenhum papel. Talvez os melhores exemplos modernos sejam os referendos ou as assembléias de cidades [town meetings] nas áreas rurais da Nova Inglaterra ${ }^{3}$ ou na Suíça. Ou, para fornecer um exemplo mais realista no nível nacional, Israel - com somente um distrito eleitoral que abrange o país inteiro-,é

\footnotetext{
2 Outra explicação para a má distribuição é que a riqueza fundiária e os proprietários de capital procuram isolar-se das demandas em favor da redistribuição provenientes dos
} 
um país em que os níveis menores do governo não coincidem com nenhuma zona territorial que tenha papel formal nos processos decisórios do governo central. Seguindo esse continuum, temos os legislativos eleitos por distritos territoriais - o modelo da maior parte das legislaturas modernas. Mesmo que esses distritos não correspondam às fronteiras dos governos territoriais (como nos sistemas ao estilo Westminster, em que a redistritalização é freqüente), pode-se esperar mais negociação territorial que nos sistemas sem distritos. Seguindo ao longo desse continuum, encontram-se os legislativos em que as fronteiras dos governos territoriais e dos distritos eleitorais correspondem uns aos outros, mas as cadeiras são alocadas de acordo com a população, como é o caso da câmara alta na Itália.

A próxima posição na Tabela 3 é ocupada pela câmara alta da grande maioria das federações modernas, incluindo os EUA. Nela, cada território tem o mesmo número de representantes diretamente eleitos, independentemente da sua população. Mas a posição que segue é ainda mais "federal": no Senado original dos EUA, assim como no moderno Bundesrat alemão, os representantes são nomeados diretamente pelos governos estaduais. Finalmente, no extremo esquerdo da Tabela 3, encontram-se os legislativos em que os representantes são nomeados diretamente, os estados pequenos estão sobre-representados e as mudanças do status quo exigem supermaiorias ou, em um caso extremo, unanimidade. Para mudanças constitucionais, o Bundesrat alemão pertence a esse grupo, assim como o Conselho de Ministros da Comunidade Européia, para as questões mais importantes. A cada posição mais à direita nesse espectro, os governos territoriais assumem maior precedência como unidades relevantes na construção das maiorias legislativas e pode-se dizer que a representação torna-se mais "federal".

A representação dos estados na elaboração de políticas do governo central faz parte da essência do federalismo (KING, 1982). Entretanto, uma definição estrita pareceria excluir o Canadá, pois suas províncias não têm representação formal como veto players nos processos decisórios do governo federal. Contudo, os governos federal e

trabalhadores urbanos.

3 Na costa Leste dos EUA (nota das tradutoras). provinciais estão claramente presos a um processo contínuo de negociação intergovernamental, que ocorre principalmente externamente às instituições do governo central. O governo central do Canadá chega até a assinar acordos contratuais com as províncias. Embora ele não seja obrigado a obter a aprovação dos governos provinciais para elaborar políticas, freqüentemente precisa agradálas, fazendo-lhes barganhas e pagamentos. Os governos centrais da Rússia e da Espanha envolvem-se diretamente em negociações bilaterais e multilaterais com os governos regionais; na Alemanha e na Austrália, há uma variedade de organismos multilaterais de negociação, formais e orientados para a elaboração de políticas específicas, que incluem os estados e o governo central.

Em suma, acordos federais são em grande parte produto de incentivos institucionais derivados de negociações anteriores, mas algumas vezes as instituições relevantes não estão identificadas na Constituição. Alguns países, como a Alemanha, o Brasil e os EUA possuem quase todos os atributos identificados acima, de (a) a (e). Porém, a Índia, a Áustria e o Canadá geralmente são considerados federações, embora suas câmaras altas não sejam nem fortes nem sobre-representadas. As credenciais federais da Índia às vezes são contestadas, porque nesse país o Primeiro-Ministro goza da autoridade constitucional para destituir os governos dos estados; porém, esse poder vem sendo empregado cada vez com menor freqüência, sem mudança constitucional.

Não obstante essas áreas cinzas, tentativas anteriores de medição comparada tratam o federalismo como um conceito binário. Inúmeros estudos comparados utilizam as classificações feitas por estudiosos das constituições (ELAZAR, 1995; WATTS, 1999) que identificam as federações baseados mais no senso comum e na experiência do que em critérios rigorosos de codificação. A última linha da Tabela 2 mostra os coeficientes de correlação de uma única variável dummy "federal" com as outras variáveis de descentralização. Não surpreende que o federalismo encontre-se positivamente correlacionado com medidas de descentralização de despesas, de receitas, de empréstimos e de políticas. Entretanto, em contraste com o conhecimento convencional, as federações não se distinguem dos sistemas unitários em termos de níveis de dependência das transferências. Além disso, o coeficiente de correlação positiva para autonomia fiscal dos governos subnacionais 
é puxado por três federações - os EUA, a Suíça e o Canadá -; outras federações com dados disponíveis a esse respeito possuem níveis muito baixos de autonomia fiscal.

A classificação tradicional das federações é muito ampla, juntando países tão diferentes como Suíça e Paquistão. Também mascara importantes variações temporais, como, por exemplo, a Nigéria, ao entrar e sair da ditadura militar, ou a Índia, à medida que a "regra do Presidente" desvaneceu-se por obsolescência. Há muito espaço para melhorarmos a medição do federalismo. Variáveis dummy sobre o federalismo devem ser consideradas com ceticismo. Embora não necessariamente funcione muito melhor, um caminho possível para a medição mais refinada seria criar medidas contínuas, adotando índices baseados nas dimensões do federalismo mencionadas acima e nos critérios de representação mostrados na Tabela 3. Mais importante ainda, na próxima seção, argumento que qualquer tentativa de medir o federalismo deve ser cuidadosamente articulada com o argumento teórico de interesse.

\section{RELACIONANDO ATEORIA E AANÁLISE DE DADOS}

Deste exercício de esclarecimento de conceitos e medidas, algumas lições destacam-se. Embora a descentralização do gasto e o federalimso estejam correlacionados com algumas das medidas alternativas, são proxies pouco precisas e potencialmente enganosas para muitos dos fenômenos discutidos pelas teorias mais importantes sobre as causas e conseqüências da descentralização. Mais importante ainda, os dados apresentados acima nos dão retratos muito diferentes da descentralização e do federalismo do que os que estão implícitos em boa parte da literatura teórica. É pouco freqüente que a descentralização fiscal e de políticas envolva um deslocamento de uma quantidade fixa de autoridade ou recursos do governo central para os governos regionais ou locais. Ao contrário, a descentralização geralmente envolve acrescentar novas camadas ou novos recursos e responsibilidades para os níveis inferiores de governo, em um contexto de superposição de esferas de autoridade.

A descentralização política também se acrescenta à natureza complexa e imbricada do governo de múltiplos níveis. Quando a autoridade sobre as políticas e sobre as finanças imbrica-se, não surpreende que a avaliação que os eleitores fazem das autoridades centrais e subnacionais também se inter-relacione. A literatura normativa sobre o federalismo fiscal, assim como as teorias constitucionais norte-americanas sobre o federalismo dual, têm tido efeitos obscurecedores. Muito freqüentemente, economistas e cientistas políticos teorizam sobre descentralização como se ela significasse uma divisão nítida de tarefas, em que o centro só entra para a provisão de bens coletivos nacionais e para corrigir desvios. As noções de federalismo que prevalecem na Ciência Política criam um problema parecido. $\mathrm{O}$ federalismo não necessariamente acarreta uma autoridade maior dos governos subnacionais sobre os impostos, gastos ou qualquer outra coisa. $\mathrm{O}$ federalismo não implica que o centro e os estados sejam soberanos, cada um protegido contra a interferência do outro. Ao contrário, as federações têm evoluído para contratos incompletos em andamento e pela sua própria natureza estão sob constante renegociação. Na maior parte das federações, o centro depende das províncias para implementar e fazer valer muitas das suas decisões e não pode efetuar mudanças do status quo em algumas áreas sem o consentimento das unidades constituintes.

Com base nessas lições, o resto deste artigo revisita diversas questões dirigidas à pesquisa empírica comparada. Para cada área de pesquisa, discute 1) as limitações dos estudos existentes; 2) formas de melhorar as conexões entre teoria e dados e 3) novos rumos para a teoria.

\section{IV.1. A descentralização endógena}

A intuição central da teoria do federalismo fiscal afirma que os benefícios da descentralização correlacionam-se positivamente com a variação geográfica nas demandas providas pelo setor público (OATES, 1972; PANIZZA, 1999). Essa linha de argumentação baseia-se em Montesquieu e Rousseau, ao enfatizar os benefícios da descentralização em territórios grandes e de populações vastas. Embora não explicitem os processos políticos por meio dos quais as demandas por descentralização são transformadas em políticas, esses autores argumentam que sistemas excessivamente centralizados em países grandes e heterogêneos terão que encarar uma grande pressão para descentralizar, se não quiserem expor-se aos riscos de secessão ou guerra civil. Alberto Alesina e seus colaboradores estendem essa lógica e examinam um intercâmbio básico entre os 
benefícios das grandes jurisdições e os custos da heterogeneidade em populações grandes (ALESINA \& SPOLAORE, 1997). Mas o tamanho grande implica custos - a dificuldade de satisfazer uma população mais diversificada. Outro ramo da literatura enfatiza o intercâmbio entre a) os benefícios da coordenação e das economias de escala e b) os benefícios de fixar os níveis dos impostos e de determinar as transferências redestributivas no nível local, nas sociedades que possuem níveis (e distribuições) de renda regionalmente heterogêneos (BOLTON \& ROLAND, 1997). Em todos esses modelos, níveis suficientemente altos de heterogeneidade geram demandas para a descentralização ou mesmo para a secessão.

Um desafio que se apresenta para testar estes argumentos encontra-se no fato de que exigem medições da heterogeneidade regional das preferências. A área territorial e a heterogeneidade lingüística são as proxies usadas nos estudos empíricos de Wallace Oates e Ugo Panizza, que revelaram uma correlação positiva com a descentralização do gasto. Esses estudos ainda mostram que a riqueza e a democracia estão positivamente associadas à descentralização do gasto.

Contudo, a descentralização do gasto tende a ser uma proxy pobre da devolução política e de políticas que tais teorias abordam. Quando a heterogeneidade étnica ou lingüística gera demandas por descentralização, as demandas tendem a dirigir-se para o locus da tomada de decisões a respeito dos currículos escolares, da segurança pública ou da introdução de eleições locais. No argumento de Bolton e Roland, que foca as preferências em relação ao locus da autoridade tributária derivadas da renda, a variável independente correta exigiria dados regionais sobre os níveis de renda e sua distribuição interpessoal e a variável dependente correta assemelhar-se-ia às variáveis de autonomia tributária da OCDE acima descritas. Contudo, os testes empíricos da teoria tendem a ser muito dificeis, pois já vimos que o tipo de autonomia tributária dos governos subnacionais concebido por essa teoria é extremamente incomum, mesmo nos países mais desenvolvidos.

De fato, os dados apresentados acima sugerem que as teorias de descentralização endógena, se bem que visam a iluminar tendências recentes, devem ir além das teorias do eleitor mediano nas quais a descentralização é conceitualmente equi- valente à secessão. Talvez seja mais relevante perguntar por que os políticos escolhem tornar o Estado mais imbricado e complexo. Por exemplo, quais incentivos conduzem os políticos do governo central a abrir mão de ter responsibilidade independente sobre a provisão de certos bens públicos e compartilhar responsibilidades com os governos locais para o financiamento da provisão descentralizada por meio de transferências? Em parte, a resposta pode relacionar-se com a potencial redução do déficit orçamentário do governo central bem como com a transferência da responsabilidade pelo mau desempenho. De modo inverso, o que explicaria a tendência dominante da primeira metade do século XX, de migração da autonomia fiscal e de políticas - especialmente relativa a impostos - dos estados e províncias para os governos centrais federais ou, mais recentemente, para os organismos intergovernamentais? Depois do trabalho pioneiro de Fritz Scharpf e seus colaboradores (SCHARPF, REISSERT \& SCHNABEL, 1976), dedica-se pouca atenção teórica ou empírica para questões relativas à natureza cada vez mais imbricada da tomada de decisões de governos centrais, regionais e locais.

Em suma, além de uns poucos estudos sobre a descentralização de despesas, trabalhos comparados sobre a descentralização endógena em matéria de impostos, política e de políticas são um território ainda sem exploração. O caminho mais promissor para uma próxima geração de pesquisas seria abordar uma gama mais ampla de variáveis de descentralização e complementar os modelos do eleitor mediano com pressupostos mais realistas sobre instituições e políticas.

\section{IV.2. Accountability, corrupção e bom governo}

Se a descentralização de fato envolvesse a transferência líquida de autoridade conforme formulado pela teoria do federalismo fiscal, poderse-ia aproximar o governo "do povo" e melhorar a informação, accountability e "responsividade" [responsiveness] em relação aos cidadãos. No entanto, quando a descentralização envolve acrescentar camadas de governo e expandir áreas de responsibilidade compartilhada, pode facilitar a transferência de "culpa" ou de créditos políticos, na prática reduzindo a accountability. Pior ainda, em países que já sofrem do fenômeno da corrupção, pode conduzir à competição pela extração de rendas e confusão sobre as bases do suborno (SHLEIFER \& VISHNY, 1993). Os es- 
tudos anteriores sobre corrupção, em que as variáveis exógenas eram medidas de descentralização do gasto e uma variável dummy "federalismo" não permitiam distinguir entre essas possibilidades (TREISMAN, 2000a; FISMAN \& GATTI, 2002). Porém, um trabalho recente de Triesman tenta lidar com os problemas potenciais associados à superposição de autoridade, utilizando uma variável que conta o número de níveis de governo, empregando uma medida de autoridade judicial e policial descentralizada (que supõe a superposição) (TREISMAN, s/d). É possível que estudos futuros apresentem avanços nesse sentido, examinando a extensão em que diferentes níveis apresentam superposição de autoridade ou, melhor ainda, autoridade regulatória.

Alguns dos argumentos mais convincentes que relacionam a descentralização com mais accountability e menos corrupção consideram a mobilidade e a competição intergovernamental como fatores que reduzem a capacidade de suborno dos governos. Porém, nem a descentralização do gasto nem o federalismo são uma proxy razoável da mobilidade do capital e da competição intergovernamental. A primeira exige alguns dados sobre as possibilidades reais dos indivíduos e das firmas realmente migrarem ou de ameaçar fazê-lo. Em boa parte do mundo, os laços étnicos e lingüísticos agem como impedimentos fortes contra a mobilidade. Fora um pequeno grupo de países ricos, a mobilidade entre jurisdições é mais freqüentemente uma ação desesperada para fugir da pobreza do que expressão de preferências sobre a provisão local de serviços ou sobre a corrupção e a migração geralmente conduz às favelas das capitais, onde a corrupção e a provisão de serviços podem ser piores ainda. Mesmo assim, os teóricos acima citados concentram-se primordialmente na mobilidade do capital, em vez da mobilidade do trabalho. Mas para que a mobilidade do capital tenha efeitos sobre a governança, os governos subnacionais precisam apresentar um grau significativo de autonomia regulatória, principalmente com relação aos impostos. Todavia, os dados apresentados acima sugerem que a autonomia da autoridade tributária dos governos subnacionais é uma ficção em muitos dos países que à primeira vista aparentam ser descentralizados. Para examinar a plausabilidade da competição entre jurisdições. Uma abordagem comum na literatura envolve examinar o tamanho e o número das jurisidições de primeiro nível, sob o pressuposto de que a mobilidade teria menos custos nas jurisdições menores. No entanto, isso não nos fornece muita informação se não for acompanhado de uma medida dos poderes fiscais dos governos. De fato, teorias simples sobre o nível ótimo de taxação fornecem bons motivos para suspeitar que haja uma correlação negativa entre o tamanho da jurisdição e a autonomia tributária.

Em todo caso, nenhum dos estudos empíricos existentes sobre corrupção ou bom governo constituem provas aceitáveis das hipóteses que vinculam a competição intergovernamental e os constrangimentos sobre os políticos locais. Em primeiro lugar, pode não ser suficiente a simples identificação de autonomia regulatória ou tributária dos governos subnacionais ou mesmo a observação de que a competição horizontal realmente acontece. Em alguns países, a estrutura do regime tributário subnacional pode encorajar a exportação de impostos ou acordos corruptos entre governos subnacionais e empresários. Além disso, embora todos os supostos benefícios da descentralização suponham ganhos em accountability, muito pouco se sabe sobre os vínculos entre os tipos de descentralização fiscal e de políticas (ou, melhor dito, superposição) e a capacidade dos eleitores de responsibilizar as autoridades locais por aquilo que fazem. Um caminho mais promissor que as regressões para fazer análise comparada seriam detalhados estudos de caso, apoiados em uma perspectiva explicitamente comparativa. Por exemplo, estudos sobre os EUA mostram que os eleitores tanto punem quanto recompensam os políticos estaduais pelos resultados macro-econômicos e fiscais obtidos (LOWRY, ALT \& FERREE, 1998), coisa que os eleitores alemães não fazem (LOHMANN, BRADY \& RIVERS, 1997). O próximo passo seria vincular explicitamente essas variações entre países com diferenças nas instituições políticas e fiscais.

\section{IV.3. Escala fiscal e redistribuição}

Um conjunto parecido de problemas tem afetado a literatura empírica comparada que examina a descentralização e o tamanho do governo. Aceite-se ou não o viés antigovernamental implícito nessa literatura, há bons motivos para acreditar que a descentralização, se facilitar a competição tributária entre governos, conduzirá a um setor público de menor tamanho. A primeira geração de estudos empíricos, no entanto, não tentou medir 
a autonomia tributária dos governos subnacionais. Oates examinou os efeitos da competição tributária sobre o tamanho do governo utilizando dados de diversos países sobre a descentralização do gasto, enquanto Cameron usou uma variável dummy de federalismo (CAMERON, 1978; OATES, 1985). Mais recentemente, Ernesto Stein (1999) distinguiu a descentralização fiscal financiada por impostos locais das transferências mesmo distinguindo entre transferências discricionárias e constitucionais - em um estudo comparado sobre o tamanho dos governos na América Latina. Rodden examinou os efeitos diferenciados das transferências e das receitas de fonte própria usando dados de uma ampla amostra, assim como usou os dados da OCDE sobre autonomia tributária acima citados para identificar países nos quais a competição tributária seria mais provável (RODDEN, 2003). Os achados sugerem que a descentralização está positivamente associada ao tamanho do governo quando financiada com transferências, mas tem um efeito neutro ou mesmo negativo nos raros casos em que a descentralização é financiada pelos impostos locais.

Uma literatura relacionada sugere que o federalismo inibe o crescimento da redistribuição e do Estado de Bem-estar Social. Parece haver apoio empírico unânime para essa proposição, mas ela limita-se a mais ou menos 15 países da OCDE e a uma variável dummy simples de federalismo ${ }^{4}$ : se os limites à redistribução são derivados da competição intergovernamental que favorece o capital sobre o trabalho e provoca nos governos locais o medo do fenômeno do welfare magnet ${ }^{5}$, o federalismo torna-se de fato uma proxy pobre. Uma explicação "federal" alternativa consiste no viés pró-status quo das federações devido aos múltiplos veto players, na era de expansão do estado de bem-estar social. Mas isso exigiria uma medida mais refinada para captar alguns dos conceitos da Tabela 3, acima. Outra teoria atraente mas ainda não testada seria a sobre-representação parlamentar de fazendeiros e das elites rurais conservadoras em detrimento dos trabalhadores urbanos; nesse caso, alguma variação do índice de

\footnotetext{
4 Para uma revisão da literature, cf. Castles (1999, p. 82).

5 Trata-se do fenômeno da atração exercida sobre as populações necessitadas, que pode provocar migração para locais com melhores programas e benefícios de assistência pública (N. T.).
}

sobrerepresentação desenvolvido por SamuelsSnyder talvez seja útil.

\section{IV.4. Gestão macro-econômica}

Finalmente, é possivel avançar tanto na conceituação quanto na utilização dos dados comparados para analisar os vínculos entre descentralização e resultados macro-econômicos, tais como déficits, inflação e, em última instância, o crescimento econômico. A literatura mais recente - caracterizada pelo ceticismo - concentrase nos problemas de coordenação e ação coletiva que complicam a gestão, o ajuste e a reforma macro-econômicos quando as decisões de gasto são descentralizadas. Mais uma vez, dados simples sobre a descentralização do gasto que não sejam acompanhadas de informaçôes sobre o marco institucional das finanças subnacionais são enganosos - os governos centrais de países com gastos muito descentralizadas freqüentemente colocam limitações muito estritas para que os governos subnacionais tomem empréstimos. Combinadas à regulação central da arrecadação dos impostos subnacionais, as limitações centrais podem fornecer ao centro instrumentos para contornar as iniciativas dos governos locais para implementar políticas fiscais que atendam seus próprios interesses mas sejam coletivamente destrutivas. É também importante examinar os efeitos de incentivo derivados das várias formas de transferências. Quando o governo central pode ameaçar reter as transferências intergovernamentais, isso pode funcionar como uma alavanca importante para constranger a indisciplina fiscal dos governos locais e amenizar problemas de cooperação intergovernamental. Por outro lado, alguns tipos de transferências intergovernamentais podem também fornecer aos políticos subnacionais (assim como seus eleitores e credores) expectativas de que no futuro o governo central assuma suas dívidas, solapando assim os incentivos para a disciplina fiscal.

Nas novas literaturas teóricas e empíricas que enfatizam riscos macro-econômicos, o federalismo joga um papel maior do que a descentralização fiscal. O federalismo combina problemas de coorenação e cooperação porque permite que os estados sejam veto players nos processos de elaboração de políticas do governo central. Não somente é possível que os estados ou províncias conduzam coletivamente sua política fiscal de modo sub-ótimo como as garantias constitucionais podem impedir a intervencão dos governos 
centrais; ou, por meio de sua representação no poder Legislativo ou nos organismos intergovernamentais de negociação, os estados beneficiados podem ter um poder de veto que impeça reformas.

Contudo, esses aspectos do federalismo são muito mal-captados por meio de uma variável dummy. Talvez uma negociação de estilo federal seja tão relevante na China quanto em qualquer federação formal e menos pronunciada na Áustria, no Paquistão ou na Nigéria durante seus períodos de regime militar do que em estados unitários como a Itália ou, cada vez mais, o Reino Unido. A natureza da barganha federativa tem sido transformada na Índia e México após a queda do Congresso e do PRI, respectivamente. Estudos de caso do federalismo e da indisciplina fiscal revelam que pequenas diferenças nos incentivos políticos, nas relações entre os poderes Executivo e Legislativo e na organização do parlamento têm consequencias importantes ${ }^{6}$. Uma meta importante para a pesquisa futura seria o desenvolvimento de variáveis que abordem as dimensões constitucionais e de representação do federalismo. Além disso, se o federalismo afeta a estabilidade macro-econômica, esse efeito é provavelmente contingente com uma série de outros aspectos políticos e institucionais, tais como a descentralização das despesas e das receitas, a autonomia subnacional para tomar empréstimos e a harmonia partidária.

Uma preocupação final relativa às regressões nas análises comparadas que as conseqüências da descentralização - mesmo se os conceitos são claros e as medidas precisas - seria o fato de que, como discutimos acima, dificilmente a organização vertical do governo é exogéna. Tanto a natureza da descentralização ou do federalismo quanto as variáveis macro-econômicas podem ser codeterminadas por outras variáveis como geografia econômica, a heterogeneidade da população, a migração, a distribuição de renda e demandas por democracia e redistribuição. Uma crescente confiança nas teorias que vinculam instituições e resultados exige que se compreenda melhor como evoluem e se estabilizam tais instituições - uma área para a qual os estudos de caso, bem informados teoricamente representam o ponto de partida mais promissor.

6 Ver, por exemplo, Rodden, Eskeland e Litvack (2003).

\section{CONCLUSÕES}

Este trabalho identificou tanto as armadilhas quanto os avanços nas tentativas de compreender a organização vertical do governo por meio da análise comparada. Uma "primeira geração" de teorias baseadas na economia do bem-estar social e na escolha pública vem sendo complementada com abordagens novas que consideram instituições e incentivos; os estudos empíricos começam a seguir o mesmo caminho. Os estudos empíricos pioneiros prestaram pouca atenção às variações nas descentralizações fiscal e política. Contudo, alguns dos seus achados se mostraram úteis: a descentralização fiscal e o federalismo não se traduzem facilmente em ganhos de eficiência e accountability, previstos pela primeira geração da teoria. A geração de estudos empíricos que se lhe seguiu vem examinando a complexidade e a diversidade da descentralização e considera a possibilidade de que diversos tipos de descentralização tenham causas e efeitos diferentes. A adequação entre a teoria e a análise empírica vem melhorando e este artigo sugeriu diversos caminhos para melhorarmos a coleta e análise de dados.

Este artigo identificou também alguns dos limites da análise empírica comparada e sustenta a relação simbiótica entre a abordagem quantitativa e os estudos de caso na análise comparada. Alguns aspectos institucionais, como os incentivos derivados de vários tipos de transferências, organização legislativa e as relações políticas entre os líderes políticos centrais e locais, devem ser analisados primeiramente por meio de estudos de caso, apoiados em hipóteses comparativas, para depois poder avançar nas análises quantitativas que comparam um grande número de países. Em geral, os analistas que produzem regressões envolvendo um grande número de casos devem ser modestos nas suas afirmações, assim como aqueles que empregam esses dados devem ser cautelosos nas interpretações que fazem. A comparabilidade das medidas adotadas algumas vezes confunde-se com sua relevância para a teoria ou para as políticas em questão, criando o perigo de que estudos afetados por conceitos mal-elaborados ou mal-medidos obscureçam as mentes e conduzam os programas de pesquisa - e também a elaboração de políticas - a caminhos pouco produtivos. Regressões com base em dados de diferentes países são as mais úteis quando tanto respondem quanto ajudam a informar estudos de caso realmente comparativos. 
Finalmente, à medida que as lições provenientes dos estudos de caso e da coleta de dados sobre os países avancem, as teorias também devem evoluir. Isso já começa a acontecer, conforme os analistas respondem aos problemas relativos a accountability, corrupção e instabilidade macroeconômica em países recentemente descentralizados. Um importante passo seria reconhecer que o melhor entendimento da descentralização dos últimos 20 anos não consiste em uma transferên- cia líquida de autoridade ou de recursos fixos dos níveis centrais de governo para os subnacionais, nem entender o federalismo como a alocação fixa de esferas de autonomia do governo central e das províncias. Um ponto de partida mais promissor para a construção teórica seria a análise das causas e efeitos da distribuição imbricada e compartilhada de autoridades política, fiscal e de políticas.

Jonathan Rodden (jrodden@mit.edu) é Professor Assistente do Departamento de Ciência Política do Massachusetts Institute of Technology (MIT).

\section{REFERÊNCIAS BIBLIOGRÁFICAS}

ALESINA, A. \& SPOLAORE, E. 1997. On the Number and Size of Nations. Quarterly Journal of Economics, v. 112, n. 4, p. 1027-1056, Nov.

BOLTON, P. \& ROLAND, G. 1997. The Breakup of Nations : A Political Economy Analysis. Quarterly Journal of Economics, v. 112, n. 4, p. 1057-1090, Nov.

BRENNNAN, G. \& BUCHANAN, J. 1980. The Power to Tax : Analytical Foundations of a Fiscal Constitution. New York : Cambridge University.

BRETON, A. \& SCOTT, A. 1978. The Economic Constitution of Federal States. Toronto : University of Toronto.

CAMERON, D. 1978. The Expansion of the Public Economy : A Comparative Analysis. American Political Science Review, Washington, D. C., n. 72, p. 1243-1261, Dec.

CASTLES, F. G. 1999. Comparative Public Policy : Patterns of Postwar Transformation. Chelenham : E. Elgar.

CHARLES, T. 1956. A Pure Theory of Local Government Expenditures. Journal of Political Economy, Chicago, Oct.

CREMER, J. \& PALFREY, T. 1999. Political Confederation. American Political Science Review, Washington, D. C., v. 93, n. 2, p. 6993, May.

DAVOODI, H \& ZOU, H.F. 1998. Fiscal Decentralization and Economic Growth : A Cross-Country Study. Journal of Urban
Economics, San Diego, v. 43, n. 2, p. 244257, Mar.

ELAZAR, D. J. 1995. From Statism to Federalism : A Paradigm Shift. Publius : The Journal of Federalism, Easton, v. 25, n. 2, p. 5-18, Spring.

FISMAN, R. \& GATTI, R. 2002. Decentralization and Corruption : Evidence Across Countries. Journal of Public Economics, v. 83, n. 3, p. 325-345, Mar.

GARMAN, C.; HAGGARD, S. \& WILLIS, E. 2001. Fiscal Decentralization : A Political Theory with Latin American Cases. World Politics, Baltimore, v. 53, n. 3, p. 205-236, Jan.

GARRETT, G. \& RODDEN, J. 2003. Globalization and Fiscal Decentralization? In : KAHLER, M. \& LAKE, D. (eds.). Globalization and Governance. Princeton : Princeton University.

HAGEN, J. \& EICHENGREEN, B. 1996. Federalism, Fiscal Restraints, and European Monetary Union. American Economic Review, Nashville, v. 86, n. 2, May.

HAYEK, F. 1939. The Economic Conditions of Interstate Federalism. In :_. Individualism and Economic Order. Chicago : University of Chicago.

HENDERSON, J. V. s/d. Data codebook. Disponível em: http://www.econ.brown.edu/ faculty/henderson/. Acesso em: 13.maio.2005. 
2000. The Effects of Urban Concentration on Economic Growth. NBER Working Paper n. 7503. Cambridge, Mass. : National Bureau of Economic Research. Disponível em : http:/ /papers.nber.org/papers/w7503.pdf. Acesso em : 13.maio.2005.

KING, P. 1982. Federalism and Federation. London : C. Helm.

LOHMANN, S.; BRADY, D. \& RIVERS, D. 1997. Party Identification, Retrospective Voting, and Moderating Elections in a Federal System : West Germany, 1961-1989. Comparative Political Studies, n. 30, p. $420-$ 449, Aug.

LOWRY, R.; ALT, J. \& FERREE, K. 1998. Fiscal Policy Outcomes and Electoral Accountability in the American States. American Political Science Review, Washington, D. C., v. 92, n. 4, p. 759-774, Dec.

OATES, W. 1972. Fiscal Federalism. New York : H. B. Jovanovich.

1985. Searching for Leviathan : An Empirical Study. American Economic Review, Nashville, n. 75, p. 748-757, Sept.

1999. An Essay on Fiscal Federalism. Journal of Economic Literature, v. 37, n. 3, p. 1124, Sept.

OECD. 1999. Taxing Powers of State and Local Government. OECD Tax Policy Studies, n. 1. Paris : Organization for Economic Cooperation and Development.

PANIZZA, U. 1999. On the Determinants of Fiscal Centralization : Theory and Evidence. Journal of Public Economics, n. 74, p. 97-139, Oct.

QIAN, Y. \& WEINGAST, B. 1997. Federalism as a Commitment to Preserving Market Incentives. Journal of Economic Perspectives, v. 11, n. 4, p. 83-92, Fall.

RIKER, W. 1964. Federalism: Origin, Operation, Significance. Boston : Little Brown.

RIKER, W. \& SCHAPS, R. 1957. Disharmony in Federal Government. Behavioral Science, n. 2 .

RODDEN, J. 2002. The Dilemma of Fiscal Federalism : Grants and Fiscal Performance around the World. American Journal of Political Science, Washington, D. C., v. 46, n. 3 , p. $670-687$, July.

2003. Reviving Leviathan : Fiscal Federalism and the Growth of Government. International Organization, v. 57, n. 4, Boston, Fall.

RODDEN, J. \& WIBBELS, E. 2002. Beyond the Fiction of Federalism. World Politics, Washington, D. C., v. 54, v. 4, p. 494-531, July.

RODDEN, J.; ESKELAND, G. \& LITVACK, J. (eds.). 2003. Decentralization and the Challenge of Hard Budget Constraints. Cambridge, Mass. : MIT.

SAMUELS, D. 2000. Concurrent Elections, Discordant Results : Presidentialism, Federalism, and Governance in Brazil. Comparative Politics, v. 33, n. 1, p. 1-20, Oct.

SAMUELS, D. \& SNYDER, R. 2001. The Value of a Vote : Malapportionment in Comparative Perspective. British Journal of Political Science, v. 31, n. 4, p. 651-671, Oct.

SCHARPF, F; REISSERT, B. \& SCHNABEL, F. 1976. Politikverflechtung: Theorie und Empirie des kooperativen Föderalismus in der Bundesrepublik. Kronberg : Scriptor Verlag.

SHLEIFER, A. \& VISHNY, R. 1993. Corruption. Quarterly Journal of Economics, v. 108, p. 599-617, Aug.

STEIN, E. 1999. Fiscal Decentralization and Government Size in Latin America. Journal of Applied Economics, v. 2, n. 2, p. 357-391, Nov.

STEPAN, A. 1999. Federalism and Democracy : Beyond the U.S. Model. Journal of Democracy, Baltimore, v. 10, n. 4, p. 19-33, Oct.

TREISMAN, D. s/d. Decentralization and the Quality of Government. Berkeley : digit.

. 2000a. The Causes of Corruption : A Cross-National Study. Journal of Public Economics, v. 76, n. 3, p. 399-457, June.

2000b. Decentralization and Inflation: Commitment, Collective Action, or Continuity? American Political Science Review, Washington, D. C., n. 94, p. 837-857, Dec.

WATTS, R. 1999. Comparing Federal Systems. Kingston : Institute of Intergovernmental Relations. 
WEINGAST, B. 1995. The Economic Role of Political Institutions : Market-Preserving Federalism and Economic Development. Journal of Law, Economics, and Organization, n. 11, p. 1-31, Apr.

WIBBELS, E. 2000. Federalism and the Politics of Macroeconomic Policy and Performance. American Journal of Political Science, Washington, D. C., n. 44, p. 687-702, Oct.

WORLD BANK. 2000. World Development Report. Washington, D. C. : The World Bank Group.

\section{OUTRAS FONTES}

IMF. Government Finance Statistics Yearbook. Washington, D. C. : International Monetary
Fund. Vários números. 
Versão dos resumos para o inglês: Miriam Adelman

COMPARATIVE FEDERALISM AND DECENTRALIZATION: ON MEANING AND MEASUREMENT

\section{Jonathan Rodden}

This article reviews and redirects the cross-country empirical literature on the causes and consequences of decentralization and federalism. A "first generation" of studies viewed decentralization as a simple zero-sum transfer of authority from the center to subnational governments, drew upon the assumptions of welfare economics and public choice theory, and employed blunt measures of expenditure decentralization and federalism. By defining several alternative forms of federalism and fiscal, policy, and political decentralization, then measuring them and exploring interrelationships across countries and over time, this paper paints more detailed pictures of decentralization and federalism that help explain the growing disjuncture between theory and cross-national evidence, pointing the way toward a "second generation" of more nuanced empirical work that takes politics and institutions seriously.

KEYWORDS: federalism; fiscal decentralization; political decentralization; policy decentralization. 
Versão dos resumos para o francês: Maria Fernanda Araújo Lisboa

FEDERALISME ET DECENTRALISATION EN PERSPECTIVE COMPAREE : SUR LES SENS ET LES MESURES

\section{Jonathan Rodden}

Cet article revoit et reoriente la littérature empirique comparée sur les causes et conséquences de la décentralisation et du fédéralisme. La « première génération » d'études concevait la décentralisation comme un jeu de résultat zéro, de transfert d'autorité du centre en direction des gouvernements sousnationaux ; elle partait des prémisses de l'économie du bien-être social et de la théorie du choix public et employait des formes peu précises pour mesurer la décentralisation de la dépense et le fédéralisme. A l'opposé, en précisant les diverses formes de fédéralisme et de décentralisation fiscale, politique et de politiques, en les mesurant et en exploitant les relations entre pays et au cours des temps, ce travail présente un portrait plus précis de la décentralisation et du fédéralisme, ce qui contribue à expliquer la croissante disjonction entre la théorie et les évidences trouvées dans différents pays. Ainsi, il pointe vers une «seconde génération » d'études empiriques plus sophistiquées, qui prenent la politique et les institutions au sérieux.

MOTS-CLES : fédéralisme; décentralisation fiscale; décentralisation politique; décentralisation de politiques; concepts. 